\title{
Identidade sentimental, historia e política en $A$ vila sulagada de Daniel Cortezón
}

\author{
Sentimental Identity, History and Politics in \\ Daniel Cortezón's A vila sulagada
}

\author{
Santiago SanjurJo Díaz \\ Universidad Complutense de Madrid \\ Departamento de Filología Alemana \\ santiago.sanjurjo@ucm.es
}

[recibido 03/03/2015, aceptado 16/07/2015]

\section{RESUMO}

Practicamente esquecida en favor da súa produción teatral, a obra novelística de Daniel Cortezón resulta de interese e actualidade, xa que nela desenvolve as súas ideas teóricas sobre identidade, historia e política. Analizando a complexa configuración destes tres conceptos en $A$ vila sulagada, intentará demostrarse como esta novela é unha metáfora do fracaso histórico de Galicia.

Palabras Chave: Identidade, Sentimentalidade, Historia, Política, Daniel Cortezón, A vila sulagada.

\section{RESUMEN}

Prácticamente olvidada en favor de su producción teatral, la obra novelística de Daniel Cortezón resulta de interés y actualidad, ya que en ella desarrolla sus ideas teóricas sobre identidad, historia y política. Analizando la compleja configuración de estos tres conceptos en $A$ vila sulagada, intentará demostrarse cómo esta novela es una metáfora del fracaso histórico de Galicia.

PAlabras Clave: Identidad, Sentimentalidad, Historia, Política, Daniel Cortezón, A vila sulagada.

\begin{abstract}
The novels of Daniel Cortezón, which have not attracted as much critical attention as his theatrical productions, are of contemporary interest as they develop his ideas on identity, history and politics. The purpose of this article is to show, through an analysis of the complex arrangement of the above three concepts, how $A$ vila Sulagada is a metaphor for the historical failure of Galicia.
\end{abstract}

KEYWORDS: Identity, Sentimentality, History, Politics, Daniel Cortezón, A vila sulagada.

SAnjurjo DíAz, S. (2015): "Identidade sentimental, historia e política en A vila sulagada de Daniel Cortezón", Madrygal. Revista de Estudios Gallegos (Madr.), 18: 123-135

SUMARIO: 1. Introdución. 2. A vila sulagada como novela. 3. Identidade. 4. Historia. 5. Política. 6. Conclusión. 7. Referencias bibliográficas. 


\section{INTRODUCIÓN}

O escritor ribadense Daniel Cortezón (1927-2009) é principalmente coñecido polo seu labor como dramaturgo e por unha serie de pezas teatrais históricas, de carácter marxista e desmitificador, como parte da creación dun teatro nacional galego. Así, obras como Prisciliano (1970), Xelmírez ou a gloria de Compostela (1974) e Os Irmandiños (1978) céntranse nalgúns dos acontecementos e das personalidades máis significativas da historia de Galicia co obxectivo de "despertar la memoria del pueblo, reactivar su inconsciente colectivo para un reencuentro consigo mismo y hacerle sentir confianza en sus propias características y en su propia "sabiduría" (Cortezón 1971: 35). Porén, esta tarefa só é comprensible en toda a súa magnitude e significación se se ten en conta que toda a obra e pensamento cortezonianos poden resumirse nun único obxectivo: a crítica e a superación dunha identidade sentimental de Galicia ${ }^{1}$. Tal e como sinala Helena Miguélez-Carballeira no seu libro Galicia, a Sentimental Nation (2013), esta identidade está baseada "on the assumption that Galicians are a nostalgic people, living in harmonious communion with their landscape or yearning for its beauty if away from it", conferíndolles "an innate capacity for poetry and an aloof humour, a way of being in the world that is both impractical and unrealistic, but also astute and reserved" (2013: 2). Lonxe de ser neutral, esta caracterización dunha suposta "esencia" do pobo galego posúe ambiguas implicacións de carácter político: mentras que, por unha banda, foi empregada polo nacionalismo para a elaboración dun "programa da cultura nacional oprimida" na súa procura da "autodiferenciación e expresión" (cf. 2013: 5), as posicións centralistas recurriron a el "as a colonial stereotype with which to stall the political articulation of Galician national insurgence" (2013: 13). Así, o que a primeira vista podería semellar outro máis dos simpáticos conxuntos de estereotipos rexionais revélase en realidade como un discurso que, atribuíndo aos galegos unha "natureza estática e pasiva", serviría para xustificar a resignación colectiva da poboación de Galicia a un estado de submisión (cf. 2013: 21), así como para desactivar "the political project for Galician nationalism that Castelao and others represented" (2013: 193).

Toda a produción ensaística de Cortezón xira precisamente arredor dunha crítica a unha concepción lírica e sentimental de Galicia que encarnan algúns teóricos do nacionalismo. Dende $O$ esprito de Galiza (1955), o primeiro ensaio que adica ao tema, ata Sobor das condicións do asalto á razón (1990) pódense atopar as liñas mestras do seu pensamento. Para o noso autor, se Galicia é non só "la más fiel imágen [sic] del más estrepitoso fracaso de un pueblo para hacer la Historia", senón tamén "el más lamentable espectáculo de una nacionalidad en pseudomorfosis" (1956: 76), isto é debido ao que dá en chamar as "caraiterístecas yin da i-alma galega": tendencia á inmovilidade, á pasividade e ao estoicismo, que se opoñen a unha "actitude yang", vital, agresiva, capaz de defender "a súa eisistenza pirmeiro, e de faguer seu proprio ámpito hexemónico dimpois" (cf. 1955: 35-36). Outro nome para esta "actitude yin" é o de "lirismo", que para Cortezón constitúe "a citra caraiterísteca do xénio galego" (1995: 48), e que define como unha mestura de rasgos románticos difusos e existenciais, marcados pola "intuizón e o sentimento" (1995: 41-42) e afastados de toda obxectividade, lóxica e racionalidade. Outros trazos que orbitan arredor da identidade sentimental galega son o humor entendido como mecanismo de defensa (1995: 123), o escepticismo de carácter ilóxico (1995: 126) e o salaio e a queixa perpetuos. Porén, o sentimento que constitúe o celme da "esencia lírica" de Galicia, "a súa máisima eispresión anímeca, o

\footnotetext{
${ }^{1}$ Xa expuxemos por extenso esta hipótese nun traballo anterior (cf. Sanjurjo 2015), polo que nesta introdución só nos limitaremos a recordar de xeito sucinto algunhas das súas claves. Alí abordamos cuestións como a relación da teoría de Cortezón coa doutros pensadores da época ou a (máis ben pouca) evolución dalgúns aspectos da mesma entre os anos 50 e 90 do século XX.
} 
seu siño espritoal distintivo" (1995: 101) é a saudade. Cortezón, que elabora a súa crítica deste concepto sobre todo a partir dos ensaios de Ramón Piñeiro², considera que a saudade, mestura de "medo e arela", (cf. 1995: 144-145) "é unha típica negación vidal”, que aparece "cando n-o intre do reduito íntimo da i-alma individoal féndese a finalidade, a teleoloxía da aución" (1995: 102). No ensaio Pantocrítica galiciana y otras cuestiones (1956), Cortezón profunda nas consecuencias da sentimentalidade para a historia de Galicia (cf. Sanjurjo Díaz 2015: 141). A súa posición poderíase resumir como radicalmente oposta á afirmación de Castelao de que a "tradición é a alma eterna de Galiza, que vive no instinto popular e nas entranas graníticas do noso chán. A tradición non é a hestoria. A tradición é a eternidade" (Castelao 1961: 38). Segundo o noso autor é preciso esquecer a tradición, que identifica co sustrato "ying" do ser e da cultura galegos, xa que esta é "anquilosamiento, debilidad y necrofagia: vive del cadaver [sic] de una historicidad ya ida, o vive resistiendo a una Historia que viene; en realidad, vive, pues, sin justificante de su propio existir" (1956: 96). Aparece aquí, pois, a tradición como autoxustificación e excusa para a queixa e a falta de acción (cf. 1956: 112), como mecanismo de resistencia na historia, pero non como terreo dende o que crear historia (cf. 1956: 136). Da tradición tamén forma parte a saudade, que califica de "enfermedad sagrada" e está asociada, como acontecerá de xeito recurrente na obra cortezoniana, coa falta de vitalidade e coa morte (cf. 1956: 109). Fica claro, pois, que para Cortezón existe unha estreita vinculación entre esta identidade sentimental que estamos describindo e a imposibilidade de acción política e, xa que logo, histórica. Para el, Galicia só ten futuro como nación se renega desta "actitude ying" e aposta pola creación dun "espíritu yang", máis racional, e dotado de "pulo, vidalidade, direución” (1956: 114), que a impela a facerse dona da súa propia historia (cf. Sanjurjo Díaz 2015: 144). Dito doutro xeito, Cortezón entende a historia como ruptura coa tradición e como superación da identidade sentimental nun acto vital, case que revolucionario, de creación política:

la nueva historicidad gallega, la que es preciso encauzar y proyectar en el futuro, ha de partir, precisamente, de una nueva serie de valores, y un rechazo de aquéllos que, por significar una acentuación de sus calidades negativas y avitales, la condujeron al enquistamiento tradicionalista y a la inhibición histórica. (1960: 167)

O obxectivo da presente contribución é analizar como as ideas de Cortezón sobre os conceptos de identidade, historia e política non só están presentes en $A$ vila sulagada, senón que resulta imprescindible telas en conta para poder entender e valorar cabalmente o significado e a importancia desta novela.

\section{A VILA SULAGADA COMO NOVELA}

A pesares de ter acadado o premio de novela "Eduardo Blanco Amor" na súa primeira edición de 1981, A vila sulagada apenas achou o recoñecemento que merece e a crítica, limitada a análises demasiado superficiais (e que non adoitan ir máis aló dun resumo, ás veces mesmo inexacto, do seu argumento), non lle fixo aínda xustiza. Así, por exemplo, atopamos que Anxo Tarrío ve nela meramente unha obra sobre "o trauma popular, xa tratado por outros novelistas e poetas, que a construcción de encoros para a xeración de electricidade produce en Galicia” (Tarrío 1994: 462). Máis acertada é a sinopse recollida no Diccionario da literatura galega, que destaca a proximidade á "reflexión filosófica e ó discurso político" dunha obra que transcorre "nunha vila galega dominada pola alienación e a impotencia duns habitantes que non poden facer fronte ás decisións políticas que os sobrepasan e que non

\footnotetext{
2 Convén sinalar, como recorda Miguélez-Carballeira, que é no piñeirismo onde "the trope of Galician sentimentality emerges as a conglomerate of images whirling around a twofold metaphorical construct", segundo o cal a identidade galega é algo "inextricably entwined with the land and landscape on the one hand, and with lyricsm on the other" (2013: 192).
} 
os teñen en conta" (Vilavedra 1995: 147-148). Olivia Rodríguez, se ben reduce a trama ao asolagamento e á desaparición de Castromiño xusto "cando está a piques de entrar na Historia", acerta ao cualificar $A$ vila sulagada de "parábola metonímica referida a Galicia" (cf. Rodríguez 2004: 373). Pódese dicir, en efecto, que se trata dunha novela de tese, xa que nela atopamos, en ocasións citadas de xeito case literal, moitas das reflexións de Cortezón sobre os temas que consideramos no apartado anterior.

Porén, é convinte sinalar que estamos tamén ante una novela coral, na que non é doado atopar unha personaxe protagonista entre as case trinta que aparecen, alén da propia vila de Castromiño. Así pois, o relato está presentado dende unha multiplicidade de perspectivas que dan conta das diversas personalidades, psicoloxías e actitudes políticas dos habitantes dunha vila que se ergue como símbolo de toda Galicia. Máis importante aínda é o feito de que Cortezón, que se confesa, non o esquezamos, nacionalista e marxista ${ }^{3}$, presta particular atención á cuestión da clase social á que pertencen as diferentes figuras, proporcionando un fresco dunha sociedade vilega conformada por labregos, obreiros e unha pequena burguesía heteroxénea. Ademais, poderíase falar de novela política polo menos en dous sentidos: por unha banda, e como xa apuntamos, $A$ vila sulagada é unha especie de ensaio novelado no que Cortezón expón a súa crítica das fatais consecuencias políticas dunha identidade sentimental de Galicia; por outra banda, nela aparecen diversas personaxes que expresan diferentes opinións e actuacións ante un mesmo feito de importantes implicacións políticas, como o é a chegada dunha modernización que ten como consecuencia a extinción da vila e dos seus habitantes.

\section{IDENTIDADE}

No primeiro capítulo da novela atópase unha especie de tratado antropolóxico no que se describe con profusión a forma de ser, isto é, os rasgos psicolóxicos máis significativos e característicos da identidade dos ribeiráns do Miño:

Nembargantes, polo xeral son líricamente lenes, salaiantes, boentes, amadoiros e sentimentais; inda que as vegadas estalen, como o rio, en paixons homicidas e feitos terríbeis e absurdos. Esto sober todo: as vegadas voltanse profundamente ilóxicos, celobremente existenciais e irracionais, o cal enche a sua vida dun contido angurioso e os situa nesa encosta do anormal, do máxico e, tamén, do teratolóxico, chea de posibilidades insospeitadas encol da xustificazón do ser do home. Tamen creen nas pantasmas. Teñ[en] medo. (Cortezón 1981: 10-11)

Como se pode comprobar, todos os epítetos presentes nesta descrición correspóndense coa identidade sentimental galega, tal e como vimos que a concibe Cortezón: unha mestura de lirismo, sentimento, alonxada da lóxica e da razón, que, ao mesmo tempo que provoca anguria e medo, tamén serve para xustificar a propia inactividade. Notable é tamén a referencia ás pantasmas, seres entre a vida e a morte, que funcionan como metáfora da actitude pasiva e agoniante dos galegos. E continúa:

Adoitan sere equilibrados, pero sempre a custa de permanecer á defensiva, dispostos a sobrevivir ao nemigo, non a bater-lo. Sospeitan sempre. Cecais por eso non poden soster a tensión vidal e, como foi dito, entolecen de maneira súpeta, adoecen, matan ou suicídan-se. [...] Tamén son supersticiosos, por suposto, e esto ten moito que ver coa sua fe relixiosa pagán, pervivinte no sochán do catolicismo exterior, ridoal, e do priscilianismo interior. (1981: 11)

\footnotetext{
3 “A pesar de sentirme nacionalista, tengo mis reparos con respecto al nacionalismo, y creo que desde el punto de vista dialéctico, con Marx y Lenin en la mano, yo soy marxista, y ante el nacionalismo, me tiento mucho la ropa" (Villapol 1997).
} 
Neste caso insístese na conexión entre carácter e política, xa que a forma de ser dos habitantes de Castromiño fainos ser pasivos e máis proclives á resistencia que á loita. Ademais, Cortezón fai fincapé nos aspectos máis escuros e existenciais desta psicoloxía, que os poden levar á loucura e mesmo á morte. Como veremos máis adiante, esta descrición resulta admonitoria do destino de Eduardo Míguez, alcalde da vila. Importantes son tamén os aspectos relixiosos (encarnados na misteriosa figura de frei Serxio, o Ermitao), que resultan dunha combinación de paganismo (culto ás serpes, crenza na metempsícose) e cristianismo (nas súas vertentes romana e priscilianista). A predilección polo irracional e o irreal ten unha curiosa correspondencia co humor, xa que ambos funcionan ao mesmo tempo como mecanismo de defensa ante unha realidade que os agrede e como excusa para unha inacción que os vai acabar levando á desaparición:

Todas estas cousas [refírese aos mitos e ás lendas], e moitas outras andrómenas e refendas, fai-los ser maxinativos, inda que soturnos; pantasiosos, temedoiros, afeitos as premonicións e aos miragres, inda que sempre dispostos á dúbida e ao humor, que é a sua máxima forma de defensa e de autodestrucción. Por eso, cecais, preocupa-lles moito a morte e os mortos, e todo canto este relacionado coa ultratumba e o ultramundo. (1981: 13)

Cortezón adiántase á análise de MiguélezCarballeira ao identificar esta identidade como un discurso ancorado e (re)creado na historiografía, xa que as descricións do primeiro capítulo, aínda que son repetidas ao longo de toda a novela polo narrador, semellan ser tamén o contido da monografía que supostamente está a escribir o boticario e historiador local Demetrio Bariloche Pelerín e que funciona como unha metáfora da (falta de) historia e, xa que logo, identidade da vila:

Acontecía que as persoalidades mais conscentes de Castromiño desexaban que a Monografía Historiográfica gravitara principalmente ao redor de Castromiño, coma un nimbeiro da sua historicidade, loubando sua groria e seu patriotismo, oufaniando-se dela e del, xa que, dunha maneira inexplicabel, e dende logo inxusta, a vila non tiña historia escrita, e dubidaba-se que a tivera da outra. (1981: 16)

Pero o discurso identitario non só é unha cuestión de historiadores, senón que tamén ten o seu reflexo na literatura. No seu ensaio inédito Ouservacións pra unha crítica encol do avidalismo na poesía galega aitoal (1962) Cortezón leva a cabo unha lectura crítica da obra poética de autores como Pimentel, Novoneyra, Díaz Castro, Xohana Torres, Manuel María e Celso Emilio Ferreiro, considerando que nela "o probrema de Galiza fica acadado e traitado [...] dunha maneira tan brandengue i acomodaticia" (1962: 96). Na súa opinión, os escritores galegos son, na súa maioría, responsables de exaltar os aspectos escuros, sentimentais e pasivos, entre os que a saudade ocupa, por suposto, un lugar principal, mais tamén de recrearse na queixa e na morte existencial, favorecendo así a resignación salaiante e o fracaso histórico de todo o pobo:

Seus poetas son, polo xeral, bagoenta e magoentamente hidrófilolíricos, e sinten predilección polas motivacións tebrosas. Agás algún, xa canso de chorar, case sempre están na noite, na saudade, na soedade, isolados, morrendo a cada intre, esmorecendo, esmorrentes, asulagados na tristura ontoloxicamente valeira das tebras alumadas e na soedade do esprito do home na compaña da sua illada existencialidade onírico-lírica. Noustante, abranguen ao mundo. Seus laídos non-o cambean, pero contribuien á autonihilación nazonal galega, ao suicidio colectivo, á fuxida xeral. (Cortezón 1981: 12)

Todos os aspectos ata aquí sinalados e que coinciden plenamente coa tradicional identidade sentimental de Galicia, reaparecen como unha sorte de leitmotivs ao longo da novela. Así, o humor, "outra d-as eispresiós do senso defesivo do home galego" (1955: 123) é en realidade un "sentimiento de impotencia, de libertad truncada" (1956: 130), e o riso, consecuencia da capacidade de cuestionar todo de xeito humorístico, revélase como a outra cara da morte e da destrución interna (cf. 1981: 148):

Moitos séculos de saber rir-se sotabarba, sotovoce, de coñecer os segredos do riso interno, do rir no ámago do esprito, entre as entreteas e a entrecodia da impotenza e da resistenza vidal. 
Coñecían a gran sabedoría: rir-se de todo, ficando perfectamente serios. Non era un arte, era unha cencia. As veces rian mentres choraban ou ao revés. (Cortezón 1981: 40)

Outra das constantes é a presencia do medo que, inspirándose na famosa descrición de Os camiños da vida de Otero Pedrayo ${ }^{4}$, abafa aos castromiñáns. Son "os medos antigos, os medos raciais, os medos relixiosos, os medos económicos das fames, os medos máxicos alapados nos recunchos do esprito" (1981: 84), que aínda tendo a súa orixe na opresión e na submisión ${ }^{5}$, acaban por callar nun medo cerval, existencial: "tiña o medo labrego, o instinto labrego de obedencia: calar e sofrir, traballar e morrer... [...] Medo de ser, de existir, ate de refolgar [...]. ¡Medo de ser e de estar!” (1981: 189). O medo é tamén a característica que conduce á inhibición e incapacidade políticas, que só se manifestan baixo a forma dunhas resistencia pasiva e dunha "renarteiría"6 que en último termo demostran seren estériles: " «iFuxide, abstenede-vos, metede a testa e os cornos no caparazón, pechade os ollos xa que non sabedes pechar os puños! [...] ¡Se ao menos forades lobos, pero sodes somentes raposos!»" (1981: 40).

A actitude existencial dos castromiñáns, alimentada no lirismo, na irracionalidade e na pasividade, acaba por estar guiada por unha especie de pulsión de morte, que mestura necrofilia e tendencias suicidas. O mesmo Bariloche relaciona a omnipresencia da morte co trasfondo pagano: "vivimos arrodeados de mortos, de lendas, de pantasmas" (1981: 110). Así, abundan as referencias á Estadea, ás Xans e á Santa Compaña. Como recorda a personaxe de Eduardo Míguez, os mortos forman parte inextricable da tradición, da identidade: " $i N o n$ hai ponlas sin tronco, nin tronco sen raídes, Ina! ¡Ina! Ina, qué somos sen a terra e os mortos?»" (1981: 97). Así, e teñamos sempre presente a crítica que fai Cortezón de Castelao, a tradición impide o pleno desenvolvemento da vida, o avance da historia, e só leva á (auto)destrución: "Este é un pobo de estroitores [...] Si, señor: estroímos todo o que está vivo e rematamos todo o que está morto ou agonizando" (1981: 42). Seguindo a lóxica deste plantexamento, os habitantes da ribeira do Miño acaban por ser eles mesmos pantasmas, mortos en vida, incapaces de rebelarse contra a condena que pende sobre eles:

- ¿Pantasmas? ¿Quén ten que voltar-se pantasma? Nesta terra non se fala mais que de pantasmas - dixo Trapote.

-Sí: pantasmas. Xa llo dixemos. Agora somos pantasmas de vivos; pero despois seremos pantasmas de mortos. (1981: 82)

A identificación coas figuras do alén é tal que a propia terra remata por converterse nunha especie de cemiterio e a vida pasiva dos habitantes non é senón unha procesión fúnebre consagrada á necrolatría:

¡Enterrade aos mortos, enterrade tamén aos vivos que están mortos e aos mortos que parecen vivos, apodrecendo-o todo!... ¡Esta terra cheira a cadaverina! ¡Dígovo-lo outra vez: somos ás parellas a Santa Compaña e as Xans, todos nós tripando por todos os camiños, e todos nós levamos o noso cadaleito ao lombo, coma os ofertados da Puebla do Caramiñal! (1981: 106)

\footnotetext{
${ }^{4}$ Resultan salientables as semellanzas entre este fragmento de Cortezón: “¡O andacio do medo espandíndo-se por todolos ancos e recantos da Terra, polos recunchos dos casales, das aldeas e das vilas, entobando aos homes, estarrecendo ás mulleres e aos nenos!" (1981: 205), e este de Otero Pedrayo: "Conforme baixaban os días ía chegando a multitude dos medos instalándose nos ocos dos caracochos, nas corredoiras, nas greas de penedos, nas salas desertas do pazo" (Otero Pedrayo 1996: 143).

5 Hai referencias explícitas ao trauma da Guerra Civil e da posterior dictadura franquista: "A muller, inda traumatizada polos vellos tempos, tiña un arrepío de inquietude" (1981: 193).

${ }^{6} \mathrm{Cf}$. "Xurde, pois, o gran probrema do silenzo. Fica engadellado, abranguido, aos grandes probremas fondamentás da psicoloxía galega, aínda por estudar. Vai dende a renarteiría á metafísica do recollimento saudoso na intimidade" (1962: 116).
} 
O punto culminante da pulsión de morte chega cando van dar comezo as obras para o asulagamento da vila: "Sonan cáseque igoal: ambalsamar i embalsamar" (Cortezón 1981: 244). Os habitantes de Castromiño, condicionados por unha tradición de anquilosamento que os ten sumidos na resignación e na queixa, amósanse incapaces de ofreceren ningún tipo de resistencia e aínda préstanse, de xeito suicida, á colaboración coa empresa que os leva á morte, colleitando as críticas do zapateiro anarquista Ulises Corbeira:

¡Benvido á fábrica de cadaleitos! ${ }^{7}$ ¡Agora temos traballo arreo para autoestroirnos! [...] ¡Cantos mais traballemos, mais axiña rematará a obra e mais pronto ficaremos afogados e pasaremos de pantasmas de vivos a pantasmas de mortos! (1981: 163)

O destino que os agarda é unha "unha morte maina, lenta, fréxeda, sulagada". A "morte sulagada" (1981: 52), que non é outra cousa máis que a consecuencia natural dunha identidade sentimental e pasiva, sempre disposta a atopar a xustificación do seu fracaso na súa forma de ser, no seu "ser asulagado" (1981: 158).

\section{HISTORIA}

A novela ábrese cunha fermosa e esperanzada aposta por un futuro que ha de traer non só unha nova historia, senón tamén un novo pobo:

Si se olla nun mapa, o río é como unha serpeante banda azul. Como a banda azul dunha bandeira que, cecais, debera ser verde, pola farturenta vexetazón da terra; pero que é branca á espera dos novos tempos e dos novos homes que escriban sober dela, no porvir, unha nova Historia. (1981: 9)

Se temos en conta todo o visto no apartado anterior, Cortezón dá esta posibilidade por frustrada. Para entender este pesimismo é preciso tamén coñecer o contexto no que foi escrita a novela. Como figura no "Introito" da cuarta e derradeira parte da súa tetraloxía teatral Castelao ou A paixón de Galiza (1997), Cortezón sentiuse profundamente decepcionado coa elevada abstención durante o plebiscito sobre o Estatuto de Autonomía do 21 de decembro de 1980, feito no que, ao seu xuízo, "Galiza se descalificaba a sí mesma" e "unha vegada máis o pobo galego se autonihilaba como nación" (1997: 30). Así, cara o final do capítulo III, atopamos unha especie de fantasmagoría entre onírica e esperpéntica, na que Ulises Corbeira leva a cabo unha crítica escarnecedora das "eleccións galegas": os votantes galegos, "pantasmas mortas" e "pantasmas vivas" conforman unha estantiga na que acoden ás furnas "da pamplina democráticoparlamentaria" e, "[c]os intereses esquencidos e [c]os dereitos ignorados" (Cortezón 1981: 67), daban unha mostra da súa "falla de memoria e dignidade colectiva" (1981: 68). No pensamento de Cortezón, sempre implacable ante o que considera "motivos justificadores de la "queja"' (1956: 112), é fundamental o concepto de "culpa", pois considera que só os galegos son responsables da súa incapacidade para erguerse como suxeito da historia:

Todos chorando, todos botándo-lle a culpa -disculpando-nos, xustificándo-nos- as forzas alleas. A culpa foi de Sabel e Fernando, a culpa é dos caciques, a culpa é dos señoritingos de Madrid, ou dos políticos, ou do demo... ¡A culpa! ¿E nós, non temos culpa?... Non-a temos porque somos un pobo de pantasmas... ¿Qué culpa poden ter as pantasmas? (Cortezón 1981: 158)

Deste xeito, consideramos que non resulta demasiado aventurado considerar $A$ vila sulagada tamén como unha novela sobre a así cha-

${ }^{7}$ Resulta moi interesante notar de novo a influencia de Otero Pedrayo, quen na súa peza teatral $O$ desengano do priorio (1952) artellara unha fábula moi similar á de $A$ vila sulagada: en Floravia, a imaxinaria capital do Ribeiro abandónase o cultivo do viño en favor da implantación da industria de fabricación de féretros, de xeito que a "cultura da vida [é] substituída pola cultura da morte" (cf. Bernárdez et al. 1999: 72-73). Loxicamente, a loubanza de tempos antergos que fai Otero Pedrayo fica moi afastada das intencións de Cortezón. 
mada Transición española e, máis en concreto, sobre a incapacidade do pobo galego para recuperar, durante o devandito proceso, as liberdades e a soberanía que acadara co Estatuto de xuño de 1936. Nesta obra, o cambio político e histórico están simbolizados na construción do encoro e no asulagamento da vila, e resulta necesario considerar esta metáfora en todas as súas significacións, xa que aquí é onde comeza a amosarse a verdadeira complexidade das ideas cortezonianas sobre a historia e o progreso.

Antes da chegada dos enxeñeiros a Castromiño, esta é "unha vila ahistórica ou, no mellor dos casos, fora da História", sempre a mercé dos "alleos, os estranxeiros, os conqueridores dela" (Cortezón 1981: 16) ${ }^{8}$. Porén, lonxe de sentirse incómodos con esta situación, os castromiñáns sofren o seu destino "con certo acomodo e abonda preguiza" (1981: 17) e confórmanse con vivir de xeito vicario a historia e identidade librescas que lles proporciona a Monografía Historiográfica de Bariloche Pelerín, no que non resulta difícil albiscar unha parodia da vertente máis culturalista (e menos política) do nacionalismo galego. Este status quo vése trastocado por completo cando a Compañía de Construcciones Termo-Hidráulicas, $S$. A. se presenta co seu proxecto de desenvolvemento industrial no val de Castromiño, representando o progreso con todas as súas contradicións.

Nos primeiros traballos teóricos de Cortezón, a súa posición sobre este concepto cífrase nunha aposta, case incondicional, pola evolución científico-técnica, entendida, dun xeito, por así dicilo, "hegeliano", como encarnación da "tarefa histórica e da Historia mesma" (Cortezón 1962: 97) que sacaría a Galicia do seu atraso económico e político, aínda que isto supuxese (ou precisamente porque implicaba) o abandono da súa identidade sentimental e rural: "O vindoiro previsíble pr-ás morfosis hestóricas futuras imprica un paulatino reixeitar d-as morfosis hestóricas yin e do siño rus da vida" (Cortezón 1955: 164). Porén, esta opinión vése matizada pola confianza depositada en acadar "unha equipolencia entre o esprito poético e a téinica centífica do cultivo ou da costruición de traitores. Teremos poetas ás parellas que téinicos na eleutrónica. Saudade ao mesmo tempo que Cencia" (1962: 98), xa que Cortezón semella ser consciente da problemática do progreso indefinido ao afirmar que o "home oicidental, facedor do xigantesco edificio téinico-centífico que sostén a civilización persente, chegará quizáves a ter noxo da téinica e da cencia" (1955: 165). Este optimismo histórico vése matizado en $A$ vila sulaga$d a$, xa que ao longo da obra, e en virtude do seu multiperspectivismo, aparecen múltiples interpretacións do progreso. Unha primeira ambivalencia aparece cando, ao coñecerse o proxecto da Compañía, algúns dos habitantes da vila obvian a destrución á que se encamiñan e só atenden ao proveito material que poidan obter:

[...] xurdira a traxedia abatendo seu fado sober da vila de Castromiño e seu val, desartellando todo proxecto no porvir [...] e afastando a vilegos e campesiños en xeral, de calquera outra preocupación que non fora a de percurar o máximo proveito das circunstanzas que conducían a morte física da vila e das terras da bisbarra. (Cortezón 1981: 17)

A estes hai que sumar os "burguesiños pequenos", deformación da pequena burguesía, que "comezaron a botar contas moi cedo" e, sen ter en conta a destrución que conleva o proceso, só pensan a curto prazo nos "sete anos de vacas gordas" e nas futuras indemnizacións que han de recibir no futuro (cf. 1981: 112-113).

No punto de vista dos enxeñeiros da compañía traslúcese toda crueza da doble face do progreso que semellaba estar ausente na obra

\footnotetext{
${ }^{8} \mathrm{Cf}$. "Tenemos que escoger y decidirnos, pues, entre seguir uncidos al carro de los vencedores (lo cual nos proporciona una brillante disculpa para toda suerte de lamentos), o tratar de conducir nuestro propio carro" (Cortezón 1956: 111).
} 
teórica de Cortezón. Así, para Euclides Trapote "a Historia era, na maioría dos casos, enormemente crudel, inda que, por suposto, tiña suas propias régulas e a súa propia lóxica -ou cecais unha metalóxica- que a xustificaba no seu quefacer" (1981: 73-74). O carácter tráxico do conflito reside no feito de que, se ben a construción do encoro contribuiría á solución de moitos dos problemas socioeconómicos da bisbarra, implica a desaparición completa de Castromiño:

¿Qué significaba Castromiño e seu val, mais todas as veigas, en comparanza e a prol do inxente problema da enerxía?... Todo elo xunto non aportaba en riqueza agrícola á productividade xeral nin un terzo do que podería aportar unha soia das grandes fábricas que necesitaban daquela enerxía... 48)

—Sí, sí pero, ¿e Castromiño? ¿E nós? (1981:

Aquí é onde Cortezón capta toda a complexidade da oposición entre tradición e historia, xa que o peso e o anquilosamento da primeira é o que fai que os os habitantes da vila, ancorados na súa inhibición histórica e sumidos "no meio da voráxen dunhas forzas que eran moi superiores as das anxurradas do Miño e ás que ao longo da historia foran feitas e sufridas" (1981: 32) por eles, sexan incapaces contrapoñer ningún tipo de acción política que lles permita tomar a iniciativa e controlar o proceso histórico co que se ven confrontados:

[...] aquelas xentes, ¿tiñan algunha pregunta que facer? ¿Non eran mais ben coma vexetais aqueles espritos botos, somentes resgardados pola renarteiría e a pasiva saxeira da canaveira que non se rompe porque se comba?... E así, pasando a torboada dos séculos por riba deles, sofrindo a Historia na tradición... ¡Sofríndo-a sin facer-la! (1981: 88)
Deste xeito, a posible oposición á catástrofe móstrase completamente inane: por unha banda, prodúcese unha mistificación do asolagamento, presentado como forza fatal dun destino inevitable (cf. 1981: 43) e novo diluvio universal (cf. 1981: 225), que ten a súa contrapartida da interpretación do progreso como unha nova divinidade ("un novo politeísmo centrado na Deusa-Enerxía e no Deus-Kilovatio") ou como a encarnación de potencias demoníacas (cf. 1981:256) ${ }^{9}$; por outra banda, as autoridades da vila que poderían ofrecer algún tipo de resistencia, encarnadas na figura do alcalde Míguez, están demasiado sumidas na inhibidora identidade sentimental, lírica e profundamente irracional ${ }^{10}$, como para poderen loitar contra o progreso no terreo que lle é propio, o da racionalidade:

Sua dialéctica [de Trapote] era como un gran muiño esnaquizando, esfarelando os graus da oposición do alcalde, e a gran moenda era o val con todo canto contiña e canto fora amoreando no tempo. Agora era a Historia engolindo-se a sí mesma. (1981: 48)

\section{POLÍTICA}

Ao longo de $A$ vila sulagada, Cortezón expón a derrota dos diversos intentos de oposición á construción do encoro, que, como xa vimos, funciona como metáfora do fracaso nacional de Galicia. Un dos rasgos máis salientables da novela é que, grazas á súa orientación multiperspectivista, ofrece un panorama de como as distintas clases se enfrontan á desaparición do pobo castromiñán. Xa se viu no apartado anterior como a pequena burguesía, pensando só no seu beneficio inmediato, traiciona os intereses da vila, sendo un claro exemplo do que Cortezón chama "lumpenburguesía", condición que acada a clase burguesa

\footnotetext{
${ }^{9}$ Nótese, en contraposición á opinión xeneralizada entre os habitantes de Castromiño, a clarividencia de Ina: “__Proxecto divino? [...] ¡Este é un proxecto capitalista! ¡Un proxecto de homes que teñen excedentes de capital e mercan a terra para domear e vender a enerxía das augas do Miño, que ate agora foi de todos" (Cortezón 1981: 109).

10 "E aqueles paifocos asturdos saían-lle [ao enxeñeiro Trapote] ao encontro co aquela recadávida de construccións e argumentacións ilóxicas, metalóxicas, absurdas" (1981: 84).
} 
"cando [...] non realiza a súa función histórica, cando non responde á obriga da súa 'xustificación' de clase, ao que ética e foronómicamente é a súa función 'directora', impulsora, progresista" (Cortezón 1990: 29-30). Os labregos, constante obxecto de crítica por parte de Corbeira, son "culpables" do seu silencio submiso e da súa complicidade seculares, condeados a un destino como lumpenproletariado urbano (cf. Cortezón 1981: 114). Neles, "bois mansos, soios isolados, insolidarios, sen xuntar-se nin unha soia vez para defender-se, para saber, para loitar" (1981: 211), xa non é posible recoñecer aos seus antepasados irmandiños que "rasoiraran coma un furacán, comoa un trebón o poder dos feudos, abatendo fortezas e castelos ate os cimentos" (cf. 1981: 151). Co comezo das obras para o asolagamento do val, chega á vila unha nova clase social, cunha actitude ben distinta á do campesiñado: o proletariado. A pesar de que as súas condicións de vida non son nin moito menos boas, algúns deles teñen conciencia de clase: "semellaban erxilar-se oufaniosos. Agromaba-lles certo orgulo, coma se foran dunha caste distinta e, por suposto, superior a dos labregos" (1981: 116) e "ollaban a terra e as cousas doutro xeito" (1981: 162). Pero, a pesar de todo, neles persiste como un lastre a súa orixe campesiña, imposibilitando a súa constitución como proletariado auténtico, capaz de converterse en suxeito da transformación política: "Xurdía do mais fondo do seu ser o labrego alapado, arreceado, renarte; o campesiño cauto, desconfiado, o emigrante que pasar a carón da historia doutros pobos sen decatar-se dela" (1981: 188).

Porén, as dúas figuras máis salientables son as de Ulises Corbeira e Eduardo Míguez, que, se ben son antagónicas, acabarán por correr unha sorte semellante. $\mathrm{O}$ zapateiro ácrata
Corbeira é o principal crítico da condición sentimental, resignada e submisa dos seus veciños. Perdedor da Guerra Civil (cf. 1981: 149) e probablemente encarnación dos ideais xuvenís de Cortezón ${ }^{11}$, rexeita con sorna a inanidade e avoga pola loita: “¡Cando mexan por un hai que berrar xustiza e percurar unha escopeta!" (1981: 127). Participará cun grupo de obreiros (entre eles Oleiros, membro do Partido Comunista) nun intento de sabotaxe que rematará fracasando. Pero no fondo é un idealista que, incapaz de rachar co sistema e sumido en fantasías destrutivas (cf. 1981: 207), non logrará producir ningún tipo de acción que trascenda a utopía. Eduardo Míguez, o alcalde de Castromiño, é o máis parecido a un protagonista da novela e a personaxe tráxica sobre a que Cortezón descarga a súa crítica da ineficacia política dun nacionalismo asentado sobre unha identidade sentimental. A súa primeira reacción ante o proxecto da Compañía é o de loitar: "—¡iLoitaremos —fremitou Míguez, rabeco, esganizando-se nunha labarada de inspiración, acenando, abranguendo ao mundo enteiro cos brazos, coma testimuña da sua decisión - ¡Loitaremos! ¡Loitaremos!” (1981: 92). Pero este pulo veráse axiña comesto pola inanidade da súa contradición esencial:

De sócato, en calquer intre [...] xurdía nel coma unha forza que o impinxira a facer cousas absurdas. Entón presentaba-se como un home audacioso e apaixoado; mentras que outras veces recuaba do que acontecía ao seu redor, alapando-se, aconchabando-se, refuxiando-se nunha valeira recadádiva de consideracións morais e de desasisadas elucubracións. (1981: 103)

Segundo vai avanzando a novela, Míguez acaba por ficar sumido nun estado que mestura todas as características que describimos como propias do sentimentalismo (abulia ${ }^{12}$, humor $^{13}$,

${ }^{11}$ Así o afirma na entrevista concecida a Roberto Pascual: "Porén, a utopía ácrata non me convenceu, precisamente por ser utópica... Pese ao seu fracaso, o marxismo segue a ser unha solución "racional" e, por suposto, "ética" (Pascual 2008: 201).

12 "Somentes atendía puntualmente as tarefas do Concello, inda que sin entusiasmo, sin pulos" (Cortezón 1981: 240).

13 "Murgullába-o un profundo senso do humor" (1981: 160). 
lirismo ${ }^{14}$, irracionalidade ${ }^{15}$ e pulsión de morte $\left.^{16}\right)$, e que o levará finalmente á tolemia máis absoluta: "Novamente aquel batelar que proviña dunha concencia desparella á realidade do ser; dunha razón oposta á realidade. Aquelo non era somentes a sinrazón [...]. Aquelo era o irracional, o comenzo da tolura" (Cortezón 1981: 133). O relato escrito polo alcalde e titulado "O Diluvio", que inclúe unha kafkiana transformación en cascuda, é unha perfecta materialización dos efectos (auto)destrutivos da identidade sentimental, saudosa tal e como a entende Cortezón:

Nos diríamos que a Saudade é o senso e o anceio panteísta do home galego n-o seu sentimento pancósmico, n-o seu desexo de identidade c-ó mundo circondante, i, asimade, a resposta á chamada biolóxica do seu instinto yin, e a resposta á chamada cósmica d-os eidos, da terra viva aitoando en yang. É, ás parellas, a persoalidade i-o anceio de despersoalizarse, a vida estremándose i-a delición d-os instintos vidás. Simultáneamente a Saudade é medo e arela: medo metafísico e arela de fusión monista: o lirismo desordeado non é máis que a súa defesa e unha d-as súas eispresiós máis doadas. (1955: 144-145)

Vistos todos estes intentos fracasados, cabe preguntarse se a novela de Cortezón contén algunha alternativa, se nela se pode atopar algunha proposta positiva. Neste sentido merece particular atención a figura de Ina, moza e futura muller de Míguez, que encarna unha mentalidade máis achegada á análise racional da realidade e radicalmente diferente á do resto das personaxes, aos que acusa de cegueira (cf. Cortezón 1981: 96). Opónse tanto á mistificación do pasado e da tradición de Bariloche e á resignación estéril e autoxustificativa de Míguez, como á carraxe e violencia utópicas de
Corbeira. Ina comparte o diagnóstico que fai o anarquista: "Olla como vivimos, desleigados, esquencidos, avergoñados de nós mesmos, da nosa língoa, da terra. Temos o esprito eivado, tolleito, entangarañado... Somentes somos bos servintes, bos mandados..." (1981: 217). Pero está moi lonxe das súas ideas e da súa "elucubración", e aposta por un novo comezo no que o pobo sexa o dono do seu destino: "iQuero unha terra ceibe e posíble, para que cando lles ensine a vila sulagada aos nosos fillos poder decir-lles: aquí comenzou unha nova história..." (1981: 217). Perante o fracaso e a morte cos que remata a novela hai que sinalar o momento clave no que se entrevé unha faísca da esperanza invocada por Ina. Trátase da construción do túnel, durante a cal, na confrontación entre os obreiros e o monte, entre o home e a natureza, se produce unha mutación na actitude de toda a vila, agora convertida, por mor da aparición dunha "conciencia de identidade, de destiño común", nunha comunidade verdadeira, capaz de realizar a súa tarefa histórica:

Non era somentes o sentimento de ter vencido a resistenza do monte, senón o da xurdia forza que todos eles representaban xuntos. Sentían a súa irmandade dunha maneira confusa, cecais intuitiva, cecais xurdindo da mesma e xorrante fonte creadora dos inconscentes arquetipos colectivos; pero decataban-se de que eles habían feito o túnel e que podían facer moitas cousas mais. (1981: 203)

Aquí vese moi claramente a proposta política, de manifesta inspiración marxista, de Cortezón: fronte á tradición e ó sentimentalismo (actitude yin), só a historia e o progreso, encarnados na construción do túnel, poden espertar as forzas (actitude yang) dunha nova clase ${ }^{17}$ de "Espartacos" e combatentes do

\footnotetext{
14 "Para Míguez a Terra -non-a terra, sinxelamente- era coma un alalá sostido, a gaita garleira, a metafísica da saudade..." (1981: 97)

15 “Nós non resolveremos noso problema se non é fora da razón” (1981: 194).

16 “A Míguez parecéu-lle que aquelo era, verdadeiramente, a entrada da lagoa Estixida que recorría o barqueiro Caronte, ou Osiris, camiño do Inferno e do ultramundo dos mortos" (1981: 245).

${ }^{17}$ Con matices: "Xa non eran labregos, inda que aínda non foran proletarios industriais" (1981: 204).
} 
"monte Medulio" (1981: 206) que sexa capaz de "crear" e "construir" a súa propia obra. Porén, Cortezón, sempre dialéctico, é consciente das complexas ambigüidades do progreso capitalista e, así, pecha este episodio cunha nota pesimista: "Eles, sempre forzando na terra, rozando-a, caletrando nela, eran agora os soldados victoriosos; pero tamén os escravos dun novo Imperio. Mais eso non-o sabían dunha maneira racional. Somentes, cecais no mellor dos casos, coma unha intuición" (1981: 207). O fracaso histórico do pobo galego, simbolizado no asolagamento de Castromiño, semella ser o do Cirolas:

Bastián Picón, o Cirolas, rapatorrós, hóspede da cadea por mor dunha folga, emigrante, galego de terra e de esprito adentro, meio vilao meio labrego, meio proletario meio gorxano, foi enterrado sin rosto no mesmo cimiterio que, có tempo, ían sulagar as augas do Miño. (1981: 208)

\section{CONCLUSIÓN}

A consideración dos conceptos de identidade, historia e política na novela $A$ vila sulaga$d a$ á luz das reflexións sobre eles contidas nos ensaios teóricos escritos por Daniel Cortezón entre 1955 e 1990 demostra a existencia dun proxecto unitario e constante de crítica das consecuencias políticas derivadas do tropo do suposto sentimentalismo galego.

Emporiso, tentamos demostrar tamén que o carácter ficcional e polifónico da alegoría da historia galega exposta na obra non contribúe senón a facer visibles as contradiccións e a complexidade do tratamento crítico dos devantidos conceptos. Deste xeito buscamos reivindicar a importancia para o actual debate encol da cuestión identitaria dun autor lamentablemente esquecido e que pode aportar reflexións interesantes que xorden desde unha perspectiva orixinal, marxinal e marxinada.

\section{REFERENCIAS BIBLIOGRÁFICAS}

Bernárdez, Carlos L. et al. (1999): Literatura galega: século XX. Vigo: A Nosa Terra.

Cortezón, Daniel (1955): O esprito da Galiza. Manuscrito inédito.

(1956): Pantocrítica galiciana y otras cuestiones. Manuscrito inédito.

(1960): De la saudade y sus formas. Nova York: Casa de Galicia.

(1962): Ouservacións pra unha crítica encol do avidalismo na poesía galega aitoal. Manuscrito inédito.

(1981): A vila sulagada. Sada: Ediciós do Castro.

(1990): “Sobor das condicións do asalto á razón”, Cadernos ribadenses 2, pp. 24-37.

(1997): Castelao ou A paixón de Galiza: IV. O pudor e a angustia. Madrid: A-Z Ediciones.

Gómez, José (2005): “Entrevista: Daniel Cortezón”, Diario de Ferrol 344, pp. 2-4.

Miguélez-Carballeira, Helena (2013): Galicia, a Sentimental Nation: Gender, Culture and Politics. Cardiff: University of Wales Press.

Otero Pedrayo, Ramón (1996): Os camiños da vida. Vigo: Galaxia.

Pascual, Roberto (2008): "Daniel Cortezón. Lembranzas dunha vida autodidacta", Madrygal. Revista de Estudios Gallegos 11, pp. 199-205 (http://revistas.ucm.es/fll/11389664/articulos/ MADR0808110199A.PDF).

RoDRíGueZ, Olivia (2004): “Literaturas galega e catalá desde 1939: para unha comparación da narrativa histórica (I)", en A. Abuín e A. Tarrío (eds.), Bases metodolóxicas para unha historia comparada das literaturas da península Ibérica. Santiago de Compostela: Universidade de Santiago de Compostela, pp. 369-383. 
SAnJurjo DíAz, Santiago (2015): "Crítica dunha identidade sentimental de Galicia: sentimento, razón e historia en Daniel Cortezón”, en C. Mejía Ruiz e X. Frías Conde (coords.); R. Pichel Gotérrez e J. Rivero Grandoso (eds.), Identidade, alteridade e exilio na literatura galega (Madrygal. Revista de Estudios Gallegos 18, número especial), pp. 139-146 (http://revistas. ucm.es/index.php/MADR/article/view/48531).

TARrío, Anxo (1994): Literatura galega: Aportacións a unha historia crítica. Vigo: Xerais.

VILAVEDRA, Dolores (1995): Diccionario da literatura galega. I. Autores. Vigo: Galaxia.

VILlaPol, Pablo (1997): “Castelao acabó por perder el contacto con la realidad gallega”, El Progreso de Lugo 01/06/1997. 